\title{
Immature Ovarian Teratoma
}

National Cancer Institute

\section{Source}

National Cancer Institute. Immature Ovarian Teratoma. NCI Thesaurus. Code C8111.

An immature teratoma arising from the ovary. It usually affects females in their first two decades of life. 